\title{
Families with children diagnosed with cancer used various strategies to create a new normal routine
}

\author{
Clarke-Steffen L. Reconstructing reality: family strategies for managing childhood cancer.J Pediatr Nurs 1997 Oct;12:278-87.
}

\section{Question}

What is the process of adaptation of families with children who are diagnosed with cancer?

\section{Design}

Grounded theory.

\section{Setting}

A university based paediatric oncology service in the US.

\section{Participants}

32 family members ( 7 mothers, 7 fathers, 6 ill children, and 12 siblings) from 7 families with children diagnosed within the previous 7-30 days with any type of cancer which had a favourable prognosis (expected 5 y survival rate $\geqslant 60 \%$ ). A 2 year old child with cancer was not interviewed. All were 2 parent families from rural communities, typically white, Protestant, and had an average of 3 children. The children with cancer had leukaemia or lymphoma and were 2-11 years old.

\section{Methods}

Semistructured home interviews were conducted within 1 week of diagnosis, within 1 week of confirmed remission, and 3 months after the second interview. The first 2 were individual interviews of 10-45 minutes; the third included the entire family and lasted 1 hour. Interviews were tape recorded and transcribed verbatim. Constant comparative analysis was used to compare data within and across families, and over time. The emerging categories were compared with existing literature, and the proposed model was presented to 2 families to see if it was consistent with their experiences.

\section{Main results}

Families used 6 strategies to create a new normal routine as they adapted to the diagnosis of childhood cancer (table).

\section{Conclusion}

Families with children diagnosed with cancer used a combination of strategies, which varied by situation, to maximise the child's health, get through the treatment period, and normalise their lives (ie, to find predictable, reliable, and comfortable routines and psychosocial contexts).

Sources of funding: National Center for Nursing Research; Sigma Theta Tau Beta Psi Chapter; Oregon Health Sciences University.

For article reprint: Dr L Clarke-Steffen, College of Nursing, Arizona State University, Box 872602, Tempe, AZ 85287-2602, USA. Fax +1 6029650212.

Strategies used by families to create a new normal routine

\begin{tabular}{ll}
\hline Strategy & Description \\
\hline $\begin{array}{l}\text { Managing the flow of information } \\
\text { Reorganising roles }\end{array}$ & $\begin{array}{l}\text { Seeking, processing, and sharing information about the illness and the family's response. } \\
\text { Minimal to dramatic changes in family roles, but usually a shift for } 1 \text { parent to take on the additional demands caused } \\
\text { by the illness (eg, rearranging work schedules, child care, and household responsibilities). } \\
\text { A process of asking what are our important values? and comparing actions with these values; when dissonance was found, } \\
\text { behaviours were changed. Families talked about feeling closer, valuing time together, and appreciating small things. } \\
\text { A shift in the time frame for the child's and family's goals from the distant future (eg, college plans) to the immediate } \\
\text { future (ie, next few days or weeks). } \\
\text { A process of understanding the illness in terms of family members' explanations of the world (eg, how illness relates to } \\
\text { spiritual beliefs, and positive and negative aspects of the illness experience). } \\
\text { Family members meet the demands of the illness by performing caregiving tasks (eg, giving medications, managing } \\
\text { treatment side effects, and making alternative arrangements for employment and household chores). }\end{array}$ \\
$\begin{array}{l}\text { Assigning meaning to the illness } \\
\text { Managing the therapeutic regimen }\end{array}$ &
\end{tabular}

\section{Commentary}

Clarke-Steffen provides an alternative direction to the consideration of family responses to childhood cancer. Rather than focusing on the definition and measurement of family coping and family coping strategies, she focuses on management style, defined as the "active, behavioural component of the family's response". ${ }^{1}$ Her approach emphasises the identification of management strategies based on the family's perceptions and definitions of the chronic illness and of the specific context of the family in making judgments about the usefulness of various strategies.

Clarke-Steffen acknowledges that the sample size was small, the population was homogeneous, the range of illness was narrow, and the length of follow up was short. She recommends further research with a larger, more diverse sample to ensure saturation of all the categories. Interestingly, Clarke-Steffen found no indication that certain tasks had to be mastered before families could move on to other tasks. Instead, families tended to rely on 1 or 2 preferred strategies throughout. Therefore, although more research is needed, we know that families do use management strategies to adapt to the diagnosis of childhood cancer, and these management strategies are likely to vary among families.

Nurses who work with children with cancer and their families can take the following messages from this study. Firstly, rather than providing unsolicited advice about potential strategies that families may find useful, nurses can best support and guide families by helping them to identify the combination of strategies that might work best for them. Secondly, nurses can be available to answer families' questions as they arise, using common everyday terms.

More work needs to be done to compare management styles among families with different structures and cultural backgrounds and when prognosis is poor or the child suffers a relapse. A useful adjunct to this work may be to determine the importance of learning style on a family's ability to assimilate and to manage the flow of disease related information and how this may affect their ability to manage the disease.

Samantha Heath, RGN, RSCN, PGDE, MA Senior Lecturer in Children's Nursing School of Health and Community Studies De Montfort University, Leicester, UK

1 Knafl KA, Deatrick JA. Family management style: concept analysis and development. $J$ Pediatr Nurs 1990;5:4-14. 